\title{
Investigation of Scale Effects on Halon and Halon Alternatives Regarding Flame Extinguishing, Inerting Concerntration and Thermal Decomposition Products
}

\author{
GÖRAN HOLMSTEDT and PETRA ANDERSSON \\ Department of Fire Safety Engineering, Lund University \\ PO Box 118, S-221 00 LUND, Sweden \\ JAN ANDERSSON \\ Bejaro $A B$ \\ Lokalvägen 11, S-240 21 Löddeköpinge, Sweden
}

\begin{abstract}
Tests have been carried out on various extinguishing agents using a tubular propane burner. The Rate of Heat Release (RHR) was measured using oxygen calorimetry. Thermal decomposition products were identified and quantified using wet chemistry and ion chromatography. Some agents were found to increase the RHR. In addition the generation of fluorinated decomposition products was higher for the replacement chemicals, and the amount of thermal decomposition products was found to be linearly related to the extinguishing time and the mass burning rate. The flammability limits of mixtures of propane and agent with air were determined in explosion chambers with volumes of 8,13 and 784 liters using sparks of 0.7-150 Joule across a 4-5 mm electrode gap. The results indicate that the combination of a relatively high spark energy in a small volume and a 1 psi combustion criterion overestimates the inerting concentration needed for room protection.
\end{abstract}

KEYWORDS: Halon replacements, Decomposition products, Inerting concentration, Flame extinction

\section{INTRODUCTION}

Studies of fire extinction have received more attention from the research community recently as a consequence of the involvement of halons in the depletion of the stratospheric ozone layer [1-4]. Although numerous chemical suppressants have been in use for more than half a century, the mechanisms by which they inhibit combustion are not yet fully 
understood [1-8], i.e. fundamental criteria for the extinction of diffusion flames and premixed flames have not yet been established. In order to establish such criteria, attention must be directed to gas phase flames, aspects of turbulence and penetration of suppressants to gas phase flames. The extinction models that have been presented range from relatively detailed theories for simplified burner configurations [9] to empirical relationships for diffusion flames and premixed flames which correlate and predict the fire-suppression effectiveness for a wide variety of gaseous, liquid and solid agents [1-4]. The empirical models, based either wholly on heat absorption processes [2,3] or on a combination of heat absorption processes and a chemical suppression factor $[1,4]$, provide a criterion for extinction which can be expressed in terms of a critical adiabatic flame temperature chosen to fit experimental data. More recently, a model which combines an energy-based approach with chemical-kinetic considerations has been published [10].

Many papers have been published on the measurement of extinction limits. Considerably less research has been devoted to near-limit phenomena and to the mechanism of non-stationary flame extinction. A better understanding of the physical action of suppression is needed in the search for alternatives to halons.

In order to collect more data on extinguishment phenomena and agent performance more than 100 tests have been conducted in this study using a tubular burner and explosion bombs. Nine different chemicals and chemical blends have been investigated.

\section{FLAME EXTINCTION}

\section{Introduction}

The most common methodology for measuring the efficiency of different fire extinguishing agents against diffusion flames is to use a laboratory cup burner [11-16]. However, the results from a cup burner test depend on many variables, e.g. fuel level, burner size, chimney size, temperature, air flow and operator. Even minor differences in equipment and technique can change cup burner values by as much as $50 \%[11,16]$. When comparing burner cup data with a developed fire scenario one must consider differences between laminar and turbulent conditions in flames, as well as differences in heat balance. For non-charring PMMA, for example, extinction was found at about $6 \%$ Halon 1301 with FMRC $50 \mathrm{~kW}$ scale apparatus with external radiation [17], in contrast to a value of about $2.5 \%$ with an NIST PMMA burner [15].

\section{Test Method}

One limitation in most of the tests referred to above is that they have been performed on a small scale, and in most cases the results are difficult to translate into real fire situations. With the introduction of the gas burner test, it was hoped that these problems could be overcome, as the scale easily could be increased and quantitative results could be obtained. The method was originally developed by NIST for the study of water spray extinction on large jet flames [18]. The method has been developed to a NORD-TEST Method NTFIRE $044[19-23]$. 


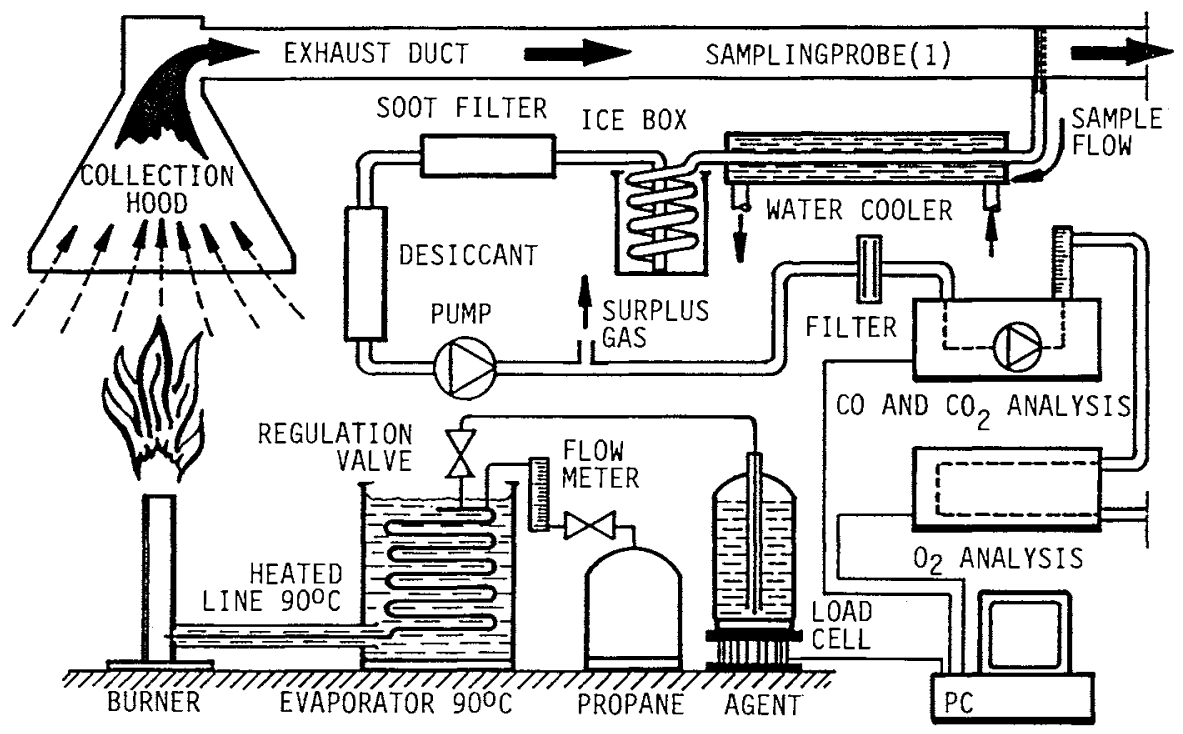

FIGURE 1. Experimental set-up

Testing was carried out using a tubular burner, where the propane gas and the extinguishing media were mixed prior to reaching the burner outlet, as shown in Figure 1. The agent was evaporated and fed into the gas flow, and the feeding rate $\left(\dot{m}_{e}\right)$ was determined by placing the pressure vessel with agent on a weighing device. The propane flow $\left(\dot{m}_{g}\right)$ was measured and controlled using a gas flow meter. The quantity of agent was increased until flame extinction occured. The specific amount of extinguishing medium required (Required Extinguishing Medium Portion, REMP $\dot{\mathrm{m}}_{\mathrm{e}} / \dot{\mathrm{m}}_{\mathrm{g}}$, i.e. the ratio of the agent quantity to fuel quantity consumed) is given as a quantitative measure of the efficiency of the agent. The lower the REMP value, the more efficient the agent. An important aspect is that the burner operates at a low Froude number, i.e. where gravitational forces dominate the flame behavior.

\section{Test Results}

Examples of various REMP values at low Froude numbers are given in Table 1. In Figure 2 the measured normalized rate of heat release (RHR) (initial $80-100 \mathrm{~kW}$ ) is shown for Halon 1301, Halon 2320 (HCFC 123), Halon 2400 (HFC 134a) Halon 3700 (HFC 227ea), Halotron I (gas blend of $98.4 \%$ w HCFC 123, $0.8 \%$ F FC14 and $0.8 \%$ w Argon) and a test blend of $65 \%$ w HFC 134a, 30\%w SF6 and $5 \%$ w $\mathrm{CO}_{2}$. Halon 1301 reduces the RHR when a small amount is added and the RHR is then almost constant until extinction occurs. Halon 2320 and Halotron I show the same characteristics as an inert gas i.e. the RHR is not affected until extinction occurs. Halon 2400, Halon 3700 and the test blend increase the RHR with increasing amounts of agent added until extinction occurs. Some of these characteristics can be observed visually in the burner cup method but can not be quantified. 


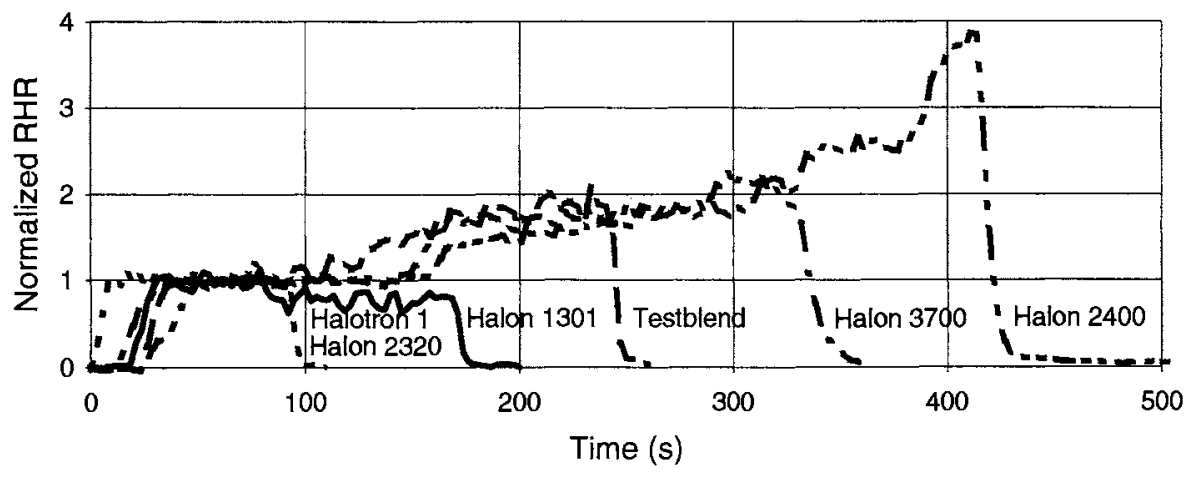

FIGURE 2. Normalized Rate of Heat Release (RHR) in tubular burner tests.

TABLE 1. REMP values for some fire suppression agents tested

\begin{tabular}{||l|l|l||}
\hline \hline Agent & REMP & SUITABLE APPLICATION \\
\hline Halon 1301 & $4-5$ & Flooding \\
Halon 1211 & $4-5$ & Streaming, local application \\
Halotron I & $6-7$ & Streaming, local application \\
Halon 2410 (HCFC 124) & $9-10$ & Streaming, local application \\
Halon 2400 (HFC 134a) & $13-15$ & Flooding \\
PFC-614 & $12-13$ & Streaming \\
Halon 3700 (HFC 227ea) & $11-12$ & Flooding \\
Test Blend & $10-12$ & Flooding \\
\hline
\end{tabular}

Reference tests carried out with the gas burner using twelve different types of dry powder [22] showed that the reproducibility in the majority of cases was better than $\pm 5 \%$. A similar reproducibility was obtained with Halon 1301 and replacement chemicals in these experiments. In addition, tests have indicated that the REMP value is independent of the RHR (between 50 and $500 \mathrm{~kW}$ ) at low Froude numbers $(<100)$ [19] and that in general there seems to be a reasonably good correlation between results from gas burner tests and those from full-scale testing [22].

\section{FORMATION OF THERMAL DECOMPOSITION PRODUCTS}

Samples for thermal decomposition product analysis were collected (by grab sampling in the exhaust duct shown in Figure 1, where the gases are well mixed) in two polypropylene gas washing bottles mounted in series. The washing bottles were filled with $20 \mathrm{ml}$ of sodium carbonate/sodium bicarbonate solution. The second bottle was used to check that all of the halides had been recovered. The halides were quantified by ion chromatography (IC). The experimentally measured concentrations of fluoride and bromide ions produced from Halon 1301 and the test blend are summarized in Table 2. The concentration, $\mu \mathrm{g}$ per litre of gas, was multiplied by the volume flow (at NTP) in the duct and normalized to the 
mass flow of propane in order to obtain the mass yields of chemical compound.

TABLE 2. Normalized generation of $\mathrm{F}^{-}, \mathrm{BR}^{-}$and $\mathrm{CO}$ at different percentage REMP values for Halon 1301 and the test blend

\begin{tabular}{||l|l|l|l|l|l|l|l|l|l|l||}
\hline & \multicolumn{3}{|l|}{ Halon 1301} & \multicolumn{1}{l|}{ Test Blend } \\
\hline REMP\% & 18 & 28 & 32 & 34 & 50 & 35 & 49 & 51 & 57 & 81 \\
\hline$\dot{\mathrm{F}} / \dot{\mathrm{m}}_{\mathrm{g}}$ & 0.02 & 0.09 & 0.07 & 0.1 & 0.14 & 0.21 & 0.8 & 0.8 & 1.1 & 1.5 \\
$\dot{\mathrm{B}} / \dot{\mathrm{m}}_{\mathrm{g}}$ & 0.02 & 0.06 & 0.06 & 0.06 & 0.07 & 0.00 & 0.00 & 0.00 & 0.00 & 0.00 \\
$\dot{\mathrm{CO}} / \dot{\mathrm{m}}_{\mathrm{g}}$ & 0.15 & 0.16 & 0.18 & 0.19 & 0.22 & 0.01 & 0.03 & 0.06 & 0.09 & 0.35 \\
\hline
\end{tabular}

In Figure 3 these results are compared with data from propane extinction taken from refs [24-28]. The literature data have been normalized by multiplying the mean concentration value in the room after extinction by the volume of the room and dividing by the mass burning rate (before extinguishing) and the extinguishing time. As can be seen in Figure 3 , there is a strong relationship between the amount of thermal decomposition products formed, the total flame extinction time [29] and the mass burning rate (fire size). The fire size varied from approx $0.3-90 \mathrm{~kW}$ in refs [24-28]. For hydrocarbons $(46 \mathrm{~kJ} / \mathrm{g})$ the yields of fluorine are: Halon 1301, $0.25 \mathrm{~g} / \mathrm{g}$; Halon 3700, $1.6 \mathrm{~g} / \mathrm{g}$ and PFC 410, $2.4 \mathrm{~g} / \mathrm{g}$. The stationary tube data at REMP values close to extinction are in reasonable agreement with the results from transient extinguishing experiments. The results clearly indicate that the generation of fluorinated decomposition products is higher (by a factor 6-10) for most of

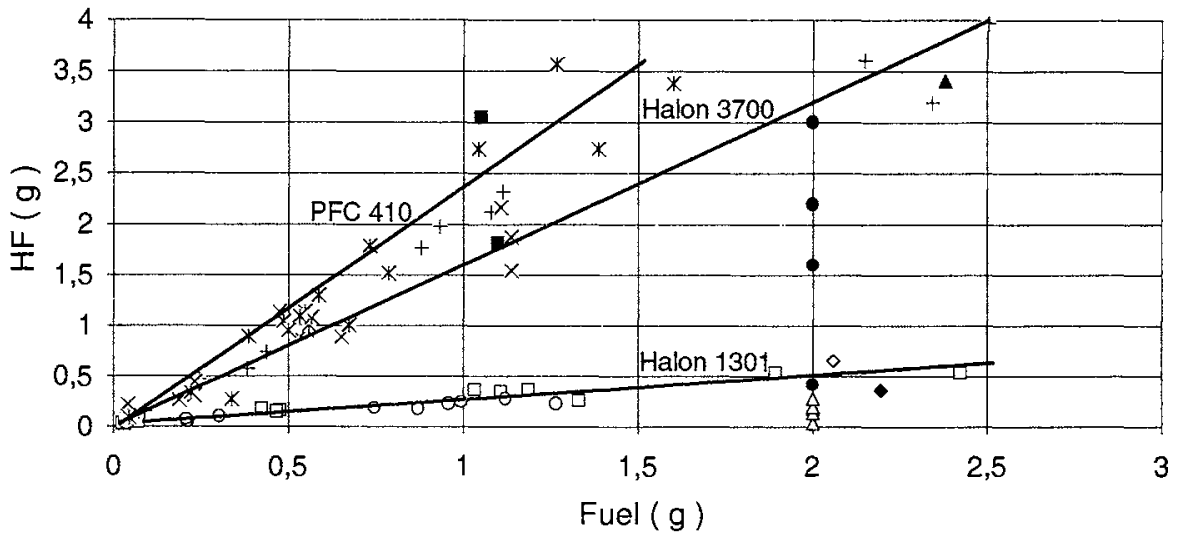

FIGURE 3. Thermal decomposition of various agents, Test Blend $50-100 \mathrm{~kW}$, + Halon 3700 burner cup 0.3-7.7 kW [25], x Halon 3700 burner cup $+20 \%$ 0.3-7.7 kW [25], ^ Halon $370088 \mathrm{~kW}[26]$, * PFC-410 0.3-7.7 kW [24], $\triangle$ Halon $130150-100 \mathrm{~kW}$, $\square$ Halon 1301 burner cup $0.3-7.7 \mathrm{~kW}$ [25], o Halon 1301 burner cup $+20 \% 0.3-7.7 \mathrm{~kW}$ [25], 0 Halon $130188 \mathrm{~kW}$ [26], Halon 1201 (HBFC 22B1) $88 \mathrm{~kW}$ [26], \& Halon 1300 (HFC 23) $88 \mathrm{~kW}[26]$. 
the replacement chemicals in agreement with the findings in refs [24-29]. Since the amount of decomposition products generated is a function of the extinction time, it is important that systems intended for replacement chemicals are optimized for the new agent. Some favourable properties of the new agents have also been observed, i.e. a lower generation of carbon monoxide and a much lower formation of soot.

\section{FLAMMABILITY LIMITS - INERTING TESTS}

\section{Introduction}

Inerting tests and applications have one common objective: to prevent the ignition of a combustible gas mixture through the addition of a suppressing agent. Theories of ignition and flame propagation which include heat transfer and diffusion processes lead to conservation equations which can, in principle, be solved to give a burning velocity if physical and chemical data are known. These equations do not, however, explain discontinuous phenomena such as flammability limits. Since inerting capability cannot be predicted with certainty, one has recourse to experiments in which the aim is to determine the limits in an apparatus-independent manner.

Test of inerting capability and flammability limits are usually performed in burettes and bombs. From the results, the minimum safe percentage of agent in an agent-air mixture at room temperature and atmospheric pressure can be derived in which all proportions of fuel and air are non-flammable. This limit usually occurs close to a stoichiometric proportion of fuel in air. The limit determined, however, depends on several parameters such as the geometry of the enclosure, the ignition source and the combustion criteria used to indicate the occurrence of flammability. As shown in refs [30-35] there is a considerable scatter in the experimental values of inerting concentrations. With Halon 1301, for example, the limit in propane-air mixtures varies from 4 vol \% (explosion burette, FMRC 1974, AC foil) [30] to $40 \mathrm{vol} \%$ (DuPont 1972, $965 \mathrm{ml} \mathrm{Bomb,} \mathrm{AC} \mathrm{spark} 1300 / \mathrm{sec}$ ) [30].

The present experiments have been carried out to determine the influence of the spark energy and combustion criteria on the inerting limit of different agents in three different enclosures; an 8-litre cube, a 13-litre sphere and a 784-litre room (1/3 scale of the ASTM room - corner test).

\section{Test Method}

The 8-litre cube. The $8-1$ (vacuum-tight) cube $(0.2 \times 0.2 \times 0.2 \mathrm{~m})$ has circular Plexiglas windows $(0.1 \mathrm{~m}$ in diameter) inserted on two opposite sides of the box. A pressure release valve, which opens at an overpressure of $0.5 \mathrm{~atm}$, is inserted into a $0.1 \mathrm{~m}$ circular opening in the top of the box. Three pairs of electrodes are placed in the box, one at a lower level, a second in the geometric centre, and a third at an upper level. The fuel (propane), agent and air are introduced into the cube by the standard partial pressure method of filling. After the gases are introduced into the box, they are mixed with a fan for 10 minutes. A spark of $0.7-150$ Joule $\left(1 / 2 \mathrm{CV}^{2}\right)$ is produced across a $4 \mathrm{~mm}$ steel electrode gap. The spark is generated by charging capacitors $(0.012,0.5$ and $2 \mu \mathrm{F})$ with high voltage $(10-15 \mathrm{kV})$. Once the capacitors are charged to the breakdown voltage in the gap they discharge 
automatically. Explosive overpressure is measured with a piezocapacitive transducer (sensitivity $1 \mathrm{~V} / \mathrm{atm}$ ) and recorded on a storage oscilloscope. Video provides visual records of the explosive event.

The 13-litre sphere. One pair of steel electrodes is mounted in the geometric centre. The fuel (propane) and agent are introduced into the evacuated sphere by the standard partial pressure technique. The air, compressed to $10-20$ atm in a $0.7-1$ cylinder is then introduced (via a fast-opening magnetic valve) through a series of mesh-covered orifices in order to obtain very intense turbulent mixing. (The equipment has been used previously to study dust explosions.) An attempt to ignite the mixture is made using a similar spark set (4 $\mathrm{mm}$ ). Explosive overpressure is measured as described above.

The 784-litre room. A $1 / 3$ scale of the ASTM room corner test is used. The door opening is hermetically sealed with a Plexiglas sheet and rubber sealant. The fuel (propane) and agent were mixed by weight ( $\pm 1 \mathrm{~g}$ accuracy) in a pressure vessel and homogenized by rotating the cylinder horizontally for 12 hours. A calculated mass of the dense fuel-agent mixture (measured by weight) is introduced into the lower part of the room at a slow rate and the excess air is ventilated out at the top of the room. After the fuel-agent mixture has been introduced, the gases are mixed with a fan placed on the floor of the room. The oxygen concentration in the room is then analysed with a paramagnetic oxygen analyser (Siemens Oxymat) and with Gas Chromatography. The mixture composition can be set to a predetermined value by adding more fuel-agent mixture or air and mixing with the fan. An attempt to ignite the mixture is made using a similar spark set $(5 \mathrm{~mm})$ mounted in the centre of the room $15 \mathrm{~cm}$ above the floor. Pressure recordings are performed as described above. Video tape provides a visual record of the explosive event.

\section{Test Results}

Figures 4 and 5 show examples of a video recording and pressure measurements for
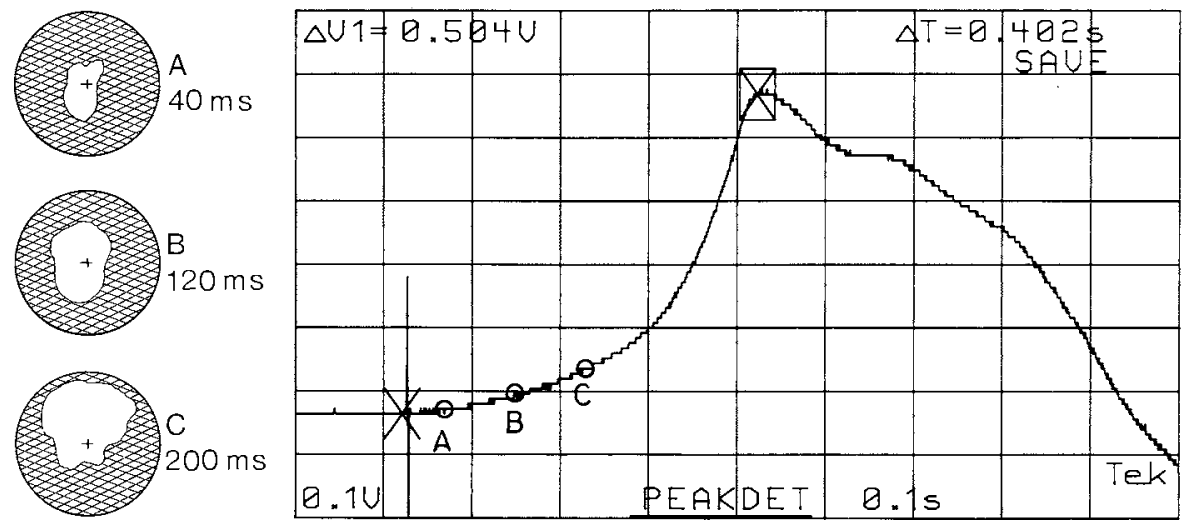

FIGURE 4. Video recordings and pressure development at $0.7 \mathrm{~J}$ spark energy, $6 \mathrm{vol} \%$ agent and $3.9 \mathrm{vol} \%$ propane for Halon 1301. 

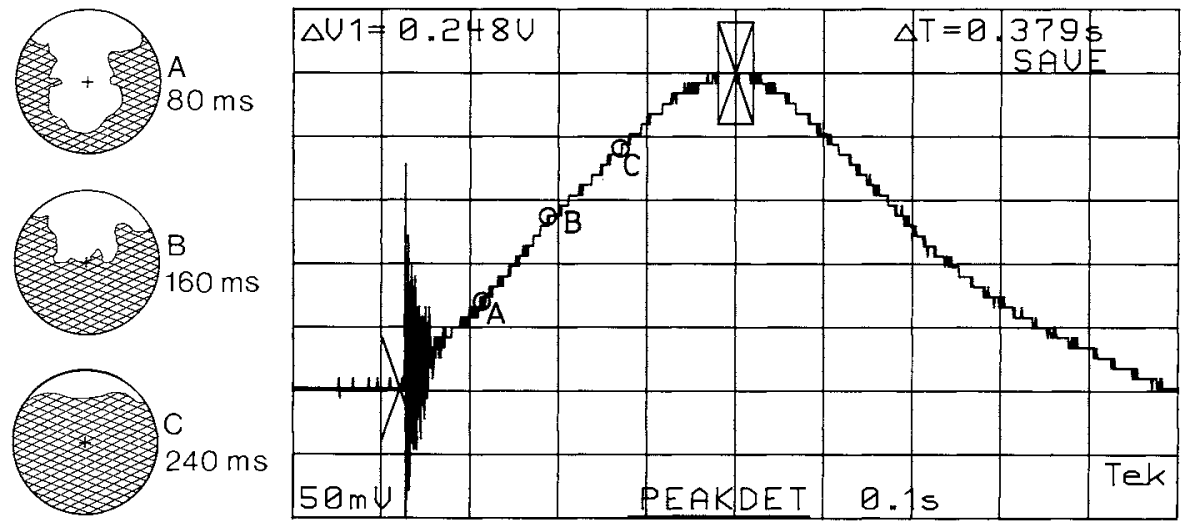

FIGURE 5. Video recordings and pressure development at $144 \mathrm{~J}$ spark energy, 7 vol\% agent and 3.9 vol\% propane for Halon 1301 .

experiments in the 8-litre cube with Halon 1301 . The uncertainty in the timing between the pressure and video recordings is estimated to be less than $10 \mathrm{msec}$. The measured inerting concentration depends on the choice of the combustion criterion used to indicate the occurrence of flammability. If a maximum pressure increase of $0.068 \mathrm{~atm}(1 \mathrm{psi})$ is chosen as a criterion the inerting concentrations in Table 3 are obtained. The inerting concentrations are given as vol \% agent in a mixture of agent, air and fuel. To obtain values on a fuel free basis the values given must be multiplied by 1.04 . The measured inerting concentrations are in reasonable agreement with values given in ref. [30]; 6.2-7 vol $\%$ for Halon 1301 in propane-air mixtures, for experiments in bombs $(5.6-7.9$ l, spark ignition and 1 psi criterion). The inerting concentration increases with increasing spark energy, by about $20-30 \%$ when the spark energy is increased from 0.7 to $144 \mathrm{~J}$, in the $8-1$ bomb, if 1 psi is used as a combustion criterion. In addition, the concentration range which will give only a small pressure increase (below $0.3 \mathrm{~atm}$, or $5 \mathrm{psi}$ ) in small bombs will be extended with increasing spark energy. In the $1 / 3$ room scale tests $(144 \mathrm{~J})$, however, no pressure increase was recorded at an inerting concentration of $7 \mathrm{vol} \%$ although a pressure increase above $0.3 \mathrm{~atm}$ was registered in the $8-1$ cube $(144 \mathrm{~J})$ with 7.0 and 7.5 vol \% Halon 1301.

TABLE 3. Inerting concentrations

\begin{tabular}{||l|l|l|l||}
\hline & Halon 1301 & Halon 2400 & Halon 3700 \\
\hline Sphere, 56 Joule & $7.1-7.2$ vol \% & & \\
Cube, 0.7 Joule & $6.0-6.5 \mathrm{vol} \%$ & $12.5-13.0 \mathrm{vol} \%$ & \\
Cube, 36 Joule & $6.5 \mathrm{vol} \%$ & $15.0-15.5 \mathrm{vol} \%$ & $11.0-11.5 \mathrm{vol} \%$ \\
Cube, 144 Joule & $8.0 \mathrm{vol} \%$ & $15.0-16.0 \mathrm{vol} \%$ & \\
$1 / 3$ room, 144 Joule & $<7$ vol \% & & \\
\hline
\end{tabular}




\section{Discussion}

Video recordings give information on the flame area as a function of time, i.e. the burned volume. As shown in Figures 4 and 5 the flame shape is dominated by natural convection. It is known that the laminar burning velocity close to the extinction limit is small compared with convective currents and that the limits of flammability depend on the gravitational force [34]. Two different kinds of flame shapes are observed; the flame expands rapidly both in the vertical and horizontal directions as in Figure 4. or the flame expands more or less only in the vertical direction. The expansion in the horizontal direction depends mainly on the entrainment of air in the upward moving vortex ring (natural convection), as shown in Figure 5. The question seems to be where the flame is quenched. In a small bomb the flame is quenched when it reaches the top of the bomb, if the spark energy is high enough, as shown in Figure 5. In the 1/3 room test the flame is quenched by entrainment of cold gas mixtures (natural convection) at a distance approximately $0-0.6 \mathrm{~m}$ above the ignition source. Thus the use of a high ignition energy may heat and burn out a gas volume which will give a pressure increase above $0.068 \mathrm{~atm}(1 \mathrm{psi})$ in a small bomb but no measurable increase in a room scenario. An initial temperature increase of $250^{\circ} \mathrm{C}$ corresponds approximately to a $20 \%$ widening of the flammability limits.

The video recordings indicate that the burned gas volume is not reproducible for mixtures close to the inerting limit, due to the stochastic nature of the processes which precede the flame expansion, i.e. the spark channel ( $0-1 \mu$ s region), hydrodynamic puff ( $1 \mu \mathrm{s}-10 \mu \mathrm{s}$ region) and flame kernel (10 $\mu \mathrm{s}-\mathrm{ms}$ region) [36]. Other observations are that the burned volume varies with agent and that the spark power as a function of time is more important for the ignition process than the total energy stored in a capacitor [36].

\section{CONCLUSIONS}

Tubular Burner tests provide a quantitative measure, the REMP value, of the extinction capacity for various streaming agents and a quantitative measure of the generation of toxic products during various stages of the extinction process. In general, a reasonably good correlation is obtained for streaming agents such as Halon 1211 and Halotron I with fullscale testing, however, more experiments are needed.

The generation of fluorinated decomposition products is higher for the investigated replacement chemicals based on HFC and FC (by factors 6-10) compared with Halon 1301. The amount of thermal decomposition products formed shows a linear relationship with the extinguishing time and the rate of heat release, i.e. the amount of fuel burned during the extinguishing process.

The combination of a relatively high spark energy, in combination with small bomb volumes, and a 1 psi combustion criterion overestimates the inerting concentration needed for room protection, and does not satisfy the demand for reproducibility. Video recordings, combined with pressure recordings, in larger volumes $\left(>0.5 \mathrm{~m}^{3}\right)$ can provide better information on how to choose a combustion criterion and a spark energy level in smaller bombs. More large-scale experiments are needed. 


\section{REFERENCES}

1. Sheinson, R.S., Penner-Hahn, J.E. and Indritz, D., "The Physical and Chemical Action of Fire Suppressants", Fire Safety Journal, 15, 437-450, (1989).

2. Ewing, C.T., Hughes, J.T., and Carhart, H.W.," The Extinction of Hydrocarbon Flames Based on the Heat-Absorption Process Which Occur in Them", Fire and Materials, $\underline{8}, 148-156,(1984)$

3. Ewing, C.T., Faith, F.R., Hughes, J.T. and Carhart, H.W., "Evidence for Flame Extinguishment by Thermal Mechanisms", Fire Technology,25, 195-212, (1989).

4. Charat, H.W., Sheinson, R.S., Tatem, P.A. and Lugar, J.R., "Fire Suppression Research in the U.S. Navy" Proceedings First International Conference on Fire Suppression Research, May 5-8, 1992, Stockholm and Borås, p 337.

5. Lovachev, L.A., Babkin, V.S., Bunev, V.A., V'Yun, A.V., Krivulin, V.N. and Baratov, A.N., "Flammability Limits; An Invited Review", Combustion \& Flame. 20, 259-289, (1973).

6. Williams, F.A., "A Review of Extinction", Fire Safety Journal, $\underline{3}$, 163-175, (1981).

7. Mitani, T., "A Flame Inhibition Theory by Inert Dust Spray", Combustion \& Flame, $\underline{43}, 243-253,(1981)$.

8. Knuth, E.L., Ni, W.F. and Seeger, C., "Molecular-Beam Sampling Study of Extinguishment of Methane-Air Flames by Dry Chemical" Combustion Science and Technology, 28, 247-262, (1982).

9. Williams, F.A., "A Unified View of Fire Suppression", Journal of Fire Flammability $5,54-63,(1974)$.

10. Tuovinen, H. and Holmstedt, G., "Computer Modelling of Extinction of MethaneAir Premixed Flames by Thermally Stable Gases" Proceedings First International Conference on Fire Suppression Research, May 5-8, 1992, Stockholm and Borås, p 37.

11 Saso, Y., Saito, N. and Iwata, V., "Scale Effect of Cup Burner on Flame Extinguishing Concentration", Fire Technology, 29, 22-33, (1993).

12. Tapscott, R.E. and Floden, J.R., "An Overview of Halon Alternatives Research" Symposium on Progress in the Development and Use of CFC Alternatives, 200th National Meeting of the American Chemical Society, paper 200, 1990.

13. Floden, J.R. and Nimitz, J.S., "Halon Replacement Program in the U.S. Air Force", 84th Annual Meeting \& Exhibition, Vancouver, British Columbia, June 16-21, 1991.

14. Sheinson, R.S., Penner-Hahn, J.E. and Indritz, D., "The Physical and Chemical 
Action of Fire Suppressants", Fire Safety Journal, 15, 437-450, (1989).

15. Gann, R., Barnes, J.D., Davis, S., Harris, J.S., Harris, R.H.Jr., Herron, J.T., Levin, B.C., Mopsik, F.I., Notarianni, K.A., Nyden, E.R. and Ricker, R.E. "Preliminary Screening Procedures and Criteria for Replacements for Halons 1211 and 1310", Nist Technical Note 1278 (1990).

16. Proposed Standard on Clean Agent Fire Extinguishing Systems, NFPA 2001.

17. Tewarson, A. and Khan, M.M., "Extinguishment of Diffusion Flames of Polymeric Materials by Halon 1301", Proceedings to Halon Alternatives Technical Working Conference, Albuquerque, New Mexico, May 12-14, 1992, p. 137.

18. McCaffrey, B.J., "Jet Diffussion Flame Suppression; An Interim Report", NBSIR84-2812.

19. Holmstedt, G., Persson, H. and Säwenmark, G., "Extinguishing of gas diffusion flames with powders and hhalons at various Froude numbers", SP Report 1986:24, Swedish National Testing Institute, Borås (In Swedish).

20. Persson, H., "Testing Method for Fire Extinguishing Power", SP Report 1989:15, Swedish National Testing Institute, Borås.

21. Nordtest Method NTFIRE/044 Approved 1991-11, Fire Protection: Fire Extinguishing Media-Powder.

22. Persson, H., "A Method for Quantitative Measurements of the Extinguishing Capability of Powders" First Conference on Fire Suppression Research, May 5-8, 1992, Stockholm and Borås, p 377

23. Andersson, J., "Halotron: A Total Concept Halon Replacement" Proceeding on Halon Alternatives Technical Working Conference, Albuquerque, New Mexico, May 12-14, 1992, p 180.

24. Ferreira, M.J., Hananska, C.P. and Pike M.T., "Thermal Decomposition Products Results Utilizing PFC-410" Proceedings to Halon Alternatives Technical Working Conference, Albuquerque, New Mexico, May 12-14, 1992, p 225.

25. Ferreira, M.J., Hananska, C.P. and Pike M.T., "An Update on Thermal Decomposition Products Results Utilizing PCF-410" International CFC \& Halon Alternatives Conference, Washington, September 30 - October 1, 1992.

26. Robin, M.L., "Evaluation of Halon Alternatives", Proceedings to Halon Alternatives Technical Working Conference, Albuquerque, New Mexico, May 12-14, 1992, p 16.

27. Fernandez, R.E., "Du Pont's Halon Alternatives Program Technical Progress" Proceedings to Halon Alternatives Technical Working Conference, Albuquerque, New Mexico, April 30 - May 1, p 39, (1991). 
28. Dierdorf, D.S., Moore, T.A. and Skaggs, S.R., "FTIR Spectroscopy for Decomposition Product Analysis of Halon Replacement Candidates" International CFC \& Halon Alternatives Conference, Washington, September 30 - October 1, 1992.

29. DiNenno, P.J., Forssell, E.W., Peatross, M.J. and Maynard, M., "Evaluation of Alternative Agents for Halon 1301 in Total Flooding Fire Suppression SystemsThermal Decomposition Product Testing" Halon Alternatives Technical Working Conferenc, Albuquerque, New Mexico 1993,p.161

30. Skaggs, S.R., "A Perspective of Measurement Techniques Utilized at the University of Lund" Letter Report Prepared for American Pacific Corporation, Las Vegas, 1993.

31. Lewis, B. and vonElbe, G., Combustion Flame and Explosions of Gases, 2nd ed. Academic Press, New York (1968).

32. Coward, H.F., and Jones, G.W., "Limits of Flammability of Gases and Vapors", U.S. Bureau of Mines, Bul 503 (1952).

33. Holmstedt, G., "The Upper Limit of Flammability of Hydrogen in Air Oxygen and Oxygen-Inert Mixtures of Elevated Pressure", Combustion and Flame, 17, 295-301 (1971).

34. Holmstedt, G., "The Influence of Natural Convection and Changes in the Physical Properties on the Limits of Flammability", Ph.D. Thesis Lund University, Sweden, LUTF D2 (TF AF 1002/1-85) (1979).

35. Heinoneu, E.W. and Skaggs, S.R., "Fire Suppression and Inertation of Halon 1301 and Replacement Agents" Technical Working Conference, Albuquerque, New Mexico, May 12-14, p 213, 1992.

36. Alde'n, M., Grafström, P., Hertz, H.M., Holmstedt, G.S., Högberg, T., Russberg, G. and Svanberg, S., "Characterization of Ultra-Short High Current Sparks for Ignition Systems", Inf. Symp on Diagnostics on Modeling of Combustion in Reciprocating Engines, Tokyo, September 4-6, 1985. 